\title{
La Gran Política y el don a la Humanidad
}

\author{
LIZBETH SAGOLS
}

La filosofía experimental como yo la vivo [...] no se detiene en una voluntad de negar. Más que esto, lo que quiere es penetrar hasta lo contrario... hasta una afirmación dionisíaca del mundo, cual éste es, sin detracción ni elección, quiere el círculo eterno [...] mi fórmula en este punto es amor fati.

Nietzsche

A primera vista, Nietzsche no es un pensador que se ocupe de la política, de hecho, nunca tuvo una práctica concreta a este respecto ni perteneció a ningún partido político. Le interesó mucho más la dimensión ético-estética e incluso metafísica de la existencia. En su obra se dirige de manera casi inevitable a la libertad de cada hombre: nos invita ante todo a asumir el riesgo de ser nosotros mismos. En esta medida, su filosofar conlleva un ethos ${ }^{1}$ más allá de toda moral establecida, un ethos que implica el gozo activo de la existencia: del ser y el devenir y, por supuesto, de la creatividad humana². Nietzsche es consciente de la soledad que exige su filosofía y se da por satisfecho con que unas cuantas 'plantas raras' — como en ocasiones llama a los filósofos_ lo sigan.

1 Entre los múltiples significados de ethos nos referimos aquí al de disposición: modo de estar en relación con la existencia en general y con la propia. Cf. J. González, El poder de eros, México, Paidós, 2000.

2 Como lo destaca Ernst Nolte, Nietzsche en sus fragmentos póstumos habla de la creación de un 'partido de la vida' destinado a garantizar la supremacía de los 'fuertes'. Pero éste partido es sólo una propuesta que nunca llega a hacerse efectiva (Nietzsche y el nietzscheanismo, tr. T. Rocha, Madrid, Alianza, 1995, p. 94). 
Pero trascendiendo esta mirada inicial, es posible encontrar que al hablar de la muerte de Dios y al proponer el superhombre, la voluntad de poder y el eterno retorno, Nietzsche se dirige a la humanidad en general, pues estas propuestas no tendrían sentido si sólo fueran aceptadas por unos cuantos; ellas implican una transvaloración y, quiérase o no, ésta ha de tener pretensiones de universalidad o simplemente no será. Los criterios básicos de valor, para ser propiamente tales, han de trascender lo circunstancial y particular. Por ello, es legítimo advertir en su filosofía tanto un pathos de soledad como un pathos implícito de universalidad. Y en efecto, Zaratustra concibe la comunicación de su verdad como el más grande don hecho a la humanidad: una entrega generosa de luz y calor, de sabiduría, amor y amistad. Aunque no todos lleguen a ser superhombres, ni asuman en igual medida la voluntad de poder y la doctrina del eterno retorno, la validez de estas propuestas tiene que ser reconocida por todos.

En consecuencia, Nietzsche se interesó por pensar a fondo la organización social que habría de permitir la realización de su filosofía. A ello atiende, precisamente, el concepto de la Gran Política. En Humano, demasiado bumano, esta expresión aparece en sentido despectivo, como el sacrificio gustoso del individuo por los ideales nacionales, lo cual le parece del todo injustificado a Nietzsche, pues a sus ojos el individuo es más importante que la nación ${ }^{3}$. Pero a partir de Más allá del bien y del mal, él dota a esta expresión de un contenido novedoso y propio: concibe la Gran Política como la liberación de los nacionalismos y la apertura a la unificación cultural y política de Europa. Más tarde, en sus fragmentos póstumos —editados como la Voluntad de poder — precisa que serán los filósofos-artistas quienes dirigirán este programa político: «A partir de nosotros habrá condiciones favorables para que $[\ldots .$.$] a [\ldots .$.$] los hombres filosóficos violentos y [a] los$ tiranos artistas [que poseen fuerza de voluntad, sabiduría, riqueza e influencia] les sea concedida una duración milenaria. [Y] sientan cerca de sí la Gran Política».

Llama la atención en esta propuesta el modo como Nietzsche pretende relacionarse con la humanidad: si bien quiere llegar a ella, consi-

3 F. Nietzsche, Humano, demasiado bumano, en Obras completas, tr. Ovejero y Mauri, Madrid, Aguilar, 1961, vol. I.

4 F. Nietzsche, La voluntad de poderío, tr. A. Froufe, Madrid, EDAF, 1980, §§ 972 y 954. 
dera que sólo a través de la violencia y la tiranía se puede lograr tal aproximación. ¿Por qué han de ser los gobernantes indefectiblemente violentos y tiránicos? Quedan aquí implícitas ideas que recorren todo el filosofar nietzscheano y de las cuales es necesario dar razón si queremos comprender el 'don a la humanidad': la guerra, la jerarquía, la desigualdad, la antidemocracia, la esclavitud e incluso la crueldad y el rechazo a la compasión. Estas ideas parecen poner en entredicho la universalidad de la transvaloración y el afán de hablar a la humanidad en general. ¿Se puede logra el acercamiento a la humanidad desde tales presupuestos? ¿Qué tanto se sostiene el pathos nietzscheano de universalidad? ¿Cómo entender, en fin, la Gran Política?

Como todas las propuestas nietzscheanas, la Gran Política tiene, a nuestro modo de ver, un carácter ambiguo, no posee un solo rostro, pues Nietzsche concibió la filosofía como búsqueda laberíntica, como experimento, juego, exploración incansable que nos lleva a recorrer múltiples caminos. Él ejerció de manera suprema el perspectivismo: el «arte de ver con múltiples ojos e instintos una sola cosa» ${ }^{5}$. Así, cabe notar que, por un lado, la Gran Política propone una organización social centrada en la creatividad cultural y en la consolidación de una casta superior - tal y como la aristocracia es entendida en Así babló Zaratustra-; mientras que por el otro, esta política propone que la organización social se centre en el imperio del Estado europeo, cuya casta superior dominará despiadadamente sobre la Tierra entera. De tal suerte que, según los de la Gran Política, ella se bifurca en predominantemente cultural o predominantemente estatal.

En Ecce homo Nietzsche afirma: «Yo soy un alegre mensajero [...] conozco tareas tan elevadas que hasta ahora faltaba el concepto para comprenderlas, sólo a partir de mí existen nuevas esperanzas. [...] El concepto de política queda totalmente absorbido en una guerra de los espíritus, todas las formas de poder de la vieja sociedad saltan por el aire [...] Sólo a partir de mí existe en la Tierra la Gran política. ¿Se quiere una fórmula de un destino como ese? [...] Se encuentra en mi Zaratustra $\left[\ldots . . . »^{6}\right.$. Se trata, pues, de una concepción renovadora de la

5 Cf. F. Nietzsche, La genealogía de la moral, tr. A. Sánchez Pascual, Madrid, Alianza, 1980.

6 F. Nietzsche, Ecce homo, tr. A. Sánchez Pascual, Madrid, Alianza, 1976, p. 124 (el subrayado es nuestro). 
política en la que ésta se aleja del poder y se entiende como 'guerra de los espíritus'. Se hace presente, así, el superhombre: poseedor de la voluntad de poder. El dinamismo de su voluntad ha de permitir la 'guerra de los espíritus' y no precisamente el poder del dominio. Para Zaratustra, la voluntad de poder es la fuerza de la libertad creativa. En principio, ella reside en todo lo vivo: tanto en las formas elevadas como en las depravadas. Pero lo que revela Zaratustra es que, en rigor, ésta requiere un 'despertar', un acto de afirmación que permita aceptarla plenamente y que consiste en asumirse a sí mismo como un sujeto capaz de querer, capaz de crear, de tener fines distintos a los impuestos por la mera necesidad, un sujeto que puede autodeterminarse: ser su propio señor. En última instancia, el fin de esta voluntad es 'seguir queriendo', no detenerse, asumir el propio ser como indeterminación o libertad radical. En esta medida, ella adquiere el dinamismo de la superación incesante. Y este dinamismo es justo lo que hace posible el anhelo del superhombre, el cual no ha de entenderse como un ser opuesto al hombre, un ser que habría de dejar atrás toda forma humana, sino (según se nos aclara en Ecce homo) ha de comprenderse como el conjunto de aquellos hombres capaces de trascender la pequeñez del hombre moderno ${ }^{7}$.

Más allá de todo idealismo y de toda profecía bioética (piénsese en el hombre mejorado con aparatos) ${ }^{8}$ podemos decir que el superhombre es el sujeto que se ha elevado gracias a su creatividad, el que deja atrás todo lamento y toda miseria gracias a una interminable guerra con su propio ser: aquel que se 'hunde en su ocaso', el que es capaz de 'morir y renacer' varias veces, que se autocrítica con dureza, que 'saja su espíritu en vivo' para entregarse a la perfección de su obra. Y desde luego, él no se autocompadece, más bien tiene siempre frente a sí, la exigencia de ser mejor. De este modo, el superhombre es ciertamente un tirano, pero su violencia y crueldad las ejerce sobre sí mismo; se causa gustosamente todo sufrimiento que le permita elevarse. Y es que Nietzsche confió siempre en el carácter redentor del sufrimiento activo, el que en vez de soportarse pasivamente, se asume por un fin superior. Este sufrimiento, lejos de hacer la vida despreciable nos permite amarla sin reservas; él exige la actividad del 'yo' y la mejoría perpe-

7 Ibid., p. 57.

8 Cf. G. Hottois, El paradigma bioético, tr. C. Monge, Barcelona, Anthropos, Barcelona, 1991. 
tua, por tanto, nos identifica con el devenir de la vida y nos acerca a los dioses. El plus del superhombre está, pues, en que él hace germinar la dimensión de lo divino en el ser humano.

¿Pero cómo ha de organizar la sociedad el filósofo-artista desde estos parámetros? Por todo lo anterior, cabe decir que en última instancia, el superhombre y la voluntad de poder representan la autonomía y plenitud de una existencia que asume su capacidad creativa. Con ello, el hombre se convierte — como dice Zaratustra- en 'una rueda que se mueve por sí misma', en 'un primer movimiento'. No es posible, entonces, dictar leyes para estos individuos ni imponerles límites, no se les puede gobernar, sino más bien propiciar y estimular. El filósofo-artista creará, así, una casta de señores que: «[...] tengan su propia esfera de vida, un exceso de fuerza para la belleza, el valor, la cultura, las maneras, hasta en el sentido más espiritual; una raza afirmadora que se pueda conceder todos los lujos [...] formando un invernadero de plantas raras y singulares»9. Esta casta estará concentrada en sí misma, no se ocupará de rebajar o esclavizar a quienes no pertenezcan a su grupo. Sus relaciones humanas estarán regidas, más bien, por la donación. Pues la voluntad de poder es, según el 'inmoralista', exceso y sobreabundancia, sobreplenitud y derroche de sí. Por ende, no puede mas que expandirse, derramarse y donar; ella es, en definitiva, una 'virtud que hace regalos'. Las relaciones humanas de esta casta superior se darían, en efecto, tal y como aparecen en el Zaratustra. En esta obra, sobresale el anhelo de comunicación, proximidad y amor. Cuando el inmoralista desciende de la montaña, el viejo sabio lo quiere convencer de la inutilidad de ir a la sociedad, lo invita a que se quede en el bosque: 'mejor ser oso entre los osos o pájaro entre los pájaros' - le dice-, y Zaratustra resistiéndose, responde: 'yo amo a los hombres'. Más aún, desde el Prólogo, Nietzsche nos advierte que quiere dirigirse a todos por igual, o bien, a ninguno. No pretende seleccionar de antemano a sus receptores, pero también es consciente de que quizá su mensaje no llegue a ningún hombre, si —como señala Heidegger en ¿Qué significa pensar? — nadie se dispone a pensarlo en profundidad ${ }^{10}$. De inicio a fin, predomina en esta

9 F. Nietzsche, La voluntad de poderío, $§ 893$.

10 M. Heidegger, ¿Qué significa pensar?, tr. H. Kahnemman, Buenos Aires, Nova, 1978 , p. 54. 
obra, el afán por encontrar un 'tú', un otro con el cual dialogar. El 'inmoralista' va primero con los hombres de la plaza pública, después carga el cadáver del volatinero y se da cuenta de que en verdad él busca compañeros vivos, entonces busca ermitaños solitarios o en pareja, más tarde habla con el joven de la montaña, con los adivinadores de enigmas y, finalmente, con los hombres superiores. Incluso al término de la obra, cuando reconoce que no ha encontrado un compañero, Zaratustra se dispone a descender de nuevo hacia los hombres.

Él establece, ciertamente, una diferencia jerárquica con quienes no escuchan su enseñanza: les llama 'los dormidos', mientras que él es un 'despierto', pero establece esta jerarquía como resultado del intento por comunicarse. Zaratustra no niega a nadie en el comienzo de su recorrido la capacidad de elevarse, es hasta que se enfrenta con la pequeñez de los mediocres cuando determina su bajeza. Su jerarquía, no parece al menos poner en cuestión el afán de aproximarse a la humanidad en general. Y es que el 'inmoralista' se concibe a sí mismo como un educador y no como un gobernante despótico: su actividad no consiste en someter o rebajar, sino en fecundar las conciencias, en estimular y 'despertar'.

Podemos suponer, así, que al igual que Zaratustra, la casta superior de la Gran Política intentará 'despertar' a los que aún duermen, a quienes no han asumido la voluntad de poder. Desde este punto de vista, la Gran Política incorpora la violencia y la crueldad como la autoexigencia de superación, y ésta ha de hacerse extensiva sólo al amigo: a quien quiera compartir la misma inquietud. «Si tienes un amigo ha de saber hacer la guerra por él y en él haz de amar al enemigo»-dice Zaratustra ${ }^{11}$. En la amistad tiene que haber lucha, cuestionamiento, contraposición, antes que acuerdo complaciente. El amigo ha de ser duro, cruel, descarnado, debe hacernos sufrir, debe enseñarnos el odio a nosotros mismos, a fin de poner la obra por encima del 'yo'. Queda desterrada, en consecuencia, toda compasión, pero no por indiferencia frente al otro, sino por una auténtica confianza en el carácter redentor del sufrimiento. La violencia y la crueldad se entienden, efectivamente, como una 'guerra de los espíritus'; ellas no atentan contra el afán de aproximarse a la humanidad.

11 F. Nietzsche, «Del amigo», en Así habló Zaraustra, tr. A. Sánchez Pascual, Madrid, Alianza, 1985. 
Quienes no logren elevarse, lo deberán a su falta de empeño, no a la esclavitud o la negación de su libertad por otros. En el Zaratustra, la jerarquía se establece por el esfuerzo; la nobleza no es otorgada por el nacimiento o cualquier otro privilegio, sino que es conquista y meta de cada quien: «[...] yo os consagro a esta nueva nobleza [...] Constituya $[\ldots .$.$] vuestro honor no el lugar de donde venís, sino el lugar a$ donde vais $[\ldots .$.$] Como proscritos debéis ser vosotros de todos los paí-$ ses de los padres y de los antepasados. El país de vuestros hijos [de vuestras conquistas] es el que debéis amar» ${ }^{12}$.

Así como en el Zaratustra hay una 'guerra de los espíritus', hay también una 'aristocracia del espíritu'. Y ésta sirve de base a una de las críticas más importantes de Nietzsche a la democracia. Para él, la igualdad de derechos promueve la nivelación y mediocridad del hombre: la uniformidad que conduce a la apatía y a la falta de autovaloración. Por tanto, él piensa que los derechos tienen que ser conquistados, pues en la lucha por adquirirlos, los hombres se forman y se superan. Como bien señala Friederich Appel, con esta crítica Nietzsche invita a salir del conformismo y la pasividad que a veces imperan en algunas democracias contemporáneas ${ }^{13}$.

Y así comprendida, la Gran Política ha de ubicarse, en verdad, más en el orden de la cultura que en el del Estado. Como advierte Jaspers, ella no contiene un plan concreto de gobierno, sino que es una tarea infinita: abierta hacia el futuro que intenta producir un movimiento que despierte los últimos fundamentos del hombre ${ }^{14}$. Puede decirse también — como quieren Deleuze y Dumoulié- que la Gran Política constituye ante todo, una llamada a la autodisciplina a fin de crear un nuevo sentido, entregándonos al pensamiento y al $\operatorname{arte}^{15}$.

Pero por otro lado, la Gran Política sí incluye un plan concreto de gobierno y una relación de dominio. En muchos otros pasajes del filosofar nietzscheano, encontramos que el filósofo-artista ha de con-

12 F. Nietzsche, 'De las tablas nuevas y viejas', en Así habló Zaraustra.

13 F. Appel, «Nietzschean Consciousness-Raising», en Nietzsche Contra Democracy, Nueva York, Universidad de Cornell, 1999.

14 K. Jaspers, Nietzsche, tr. E. Estiú, Buenos Aires, Sudamericana, 1973, p. 370.

15 G. Deleuze, La lógica del sentido, tr. M. Morey, Barcelona, Paidós, pp. 90-91. C. Dumoulié, Nietzsche y Artaud. Por una ética de la crueldad, tr. S. Mastrángelo, México, Siglo XXI, 1996, pp. 228-232. 
seguir que Europa impere sobre la Tierra entera. "Yo desearía leemos en Más allá del bien y del mal- que Europa [...] se volviera amenazadora $[. .$.$] [y adquiriera ]$ una voluntad única mediante $[\ldots]$ una nueva casta $[\ldots . .[$ que pudiera proponerse metas para milenios para que por fin acabasen [...] la división en pequeños Estados y [las] veleidades dinásticas y democráticas. El tiempo de la política pequeña ha pasado: ya el próximo siglo trae consigo la lucha por el dominio de la Tierra — la coacción a hacer una política grande» ${ }^{16}$. Para este dominio europeo habrá que crear un Estado despótico ${ }^{17}$ y enfrentar guerras militares entre naciones ${ }^{18}$. Y Nietzsche no se arredra ante ello, más bien lo ve con la frialdad del 'espíritu libre' que conoce su meta y no le importan los sacrificios; está consciente de que es necesario atacar a pueblos enteros.

Desde este punto de vista, la casta superior no tendrá como tarea principal la cultura, sino la selección de los hombres más sanos, temibles y superiores, además, habrá de subyugar a los inferiores convirtiéndolos en esclavos, quitándoles su libertad. Pues lo esencial de una buena aristocracia es el convencimiento de que la sociedad y la humanidad misma, sólo tienen derecho a existir como instrumentos, como esclavas de los hombres superiores ${ }^{19}$. Y sobre todo, esta casta - pesa en verdad decirlo - habrá de exterminar a los débiles. «Es caro y terrible el precio que hay que pagar siempre que [...] el filósofo [...] no es el medio de selección y de educación [...]. Hay en el ser humano, como en toda especie animal, un excedente de tarados, enfermos, degenerados, decrépitos dolientes [...] Las religiones [...] por principio toman partido en función de los malogrados [...] aquellos que deberían perecer $[. .$.$] [Los religiosos no han sido] lo bastante aristocráticos como$ para ver la jerarquía abismal y la diferencia de rango existente entre

16 F. Nietzsche, Más allá del bien y del mal, tr. A. Sánchez Pascual, Madrid, Alianza, $1978, \S 208$.

17 La idea despótica del Estado queda expresada en este fragmento: «Sólo las pinzas de acero del Estado comprimen, en las grandes masas, a los unos contra los otros, de tal modo que [...] aquella separación [...] de la sociedad - con [...] su construcción piramidal, se tiene que producir por sí misma» (F. Nietzsche, Fragmentos póstumos, 9, 154, citado en K. Jaspers, op. cit., p. 372).

18 F. Nietzsche, Fragmentos póstumos, 5, 313 y 8, 192, citados en K. Jaspers, op. cit., p. 384 .

19 F. Nietzsche, Más allá del bien y del mal, § 258. 
hombre y hombre: tales son los hombres que han dominado hasta ahora, con su 'igualdad ante Dios' ${ }^{20}$.

Resulta inevitable admitir que la Gran Política conlleva, así, una ruptura con la humanidad; ésta ha de ser seleccionada y dividida, no hay universalidad posible. De hecho, Nietzsche considera en múltiples ocasiones, que la igualdad es sólo un decreto de Dios, y que al morir él imperan la diferencia y la oposición entre los hombres. Desde este punto de vista, lanza sus críticas más duras a la democracia como un gobierno decadente, corrompido, rebajador del ímpetu natural del individuo por prevalecer y dominar, un gobierno en el que imperan los vulgares y los estúpidos ${ }^{21}$.

Nietzsche piensa también ahora la jerarquía interhumana de un modo distinto a como aparecía en el Zaratustra. En la Genealogía de la moral pone como condición necesaria de la nobleza la procedencia de ancestros 'superiores'; exige un nacimiento alto, una aristocracia de sangre. Su mensaje no es, entonces, para todos, más bien, él ha puesto condiciones muy específicas a sus receptores. $\mathrm{Y}$ al contrario de lo que veíamos en la perspectiva anterior, la casta de los superiores tiene vínculos de total indiferencia con los inferiores: niega por principio, la libertad y superación del pueblo y quiere aniquilar a los enfermos.

¿Cómo explicar esta idea de la casta superior? ¿No está constituida también por la voluntad de poder, la cual es creatividad y donación? En las obras posteriores a Así habló Zaratustra, la voluntad de poder adquiere una novedad preocupante. Principalmente en Más allá del bien y del mal y en la Genealogía, ella se presenta como: «[...] apropiación, ofensa, avasallamiento de lo que es extraño y más débil, opresión, dureza, imposición de formas propias, anexión, y al menos en el caso más suave explotación»22. Y es que a partir de Más allá del bien y del mal, Nietzsche reflexiona abiertamente desde el nihilismo, e incluso lleva éste al extremo. No reflexiona sólo desde la ausencia de valores trascendentes, sino que se propone destruir, aniquilar. Su filosofía discurre por una vía distinta a la anterior.

En consecuencia, el superhombre ya no se concibe como el creador, se emparienta más bien con la inquietante figura de la 'bestia rubia':

20 Ibid., § 62.

21 F. Nietzsche, Fragmentos póstumos, 15, 232, citado en K. Jaspers, op. cit., p. 380.

22 F. Nietzsche, Más allá del bien y del mal, § 259. 
modelo de salud y jovialidad frente a toda represión de la cultura tradicional. Esta bestia no se concentra propiamente en destruir al débil, pues también es afirmativa. «Toda moral noble surge de un triunfante sí dicho frente a sí mismo», nos dice Nietzsche ${ }^{23}$. Sin embargo, la afirmación de la 'bestia rubia' es unilateral, sin diálogo con el otro, con el extraño. Tal y como aparece en la Genealogía, ella es un ser sin conciencia del tiempo, de la muerte, del peligro y del otro: está gobernada por la seguridad ciega de los instintos. Para ella, sólo valen los hombres que pertenecen a su grupo. Con éstos es donante y noble, pero ante cualquier extraño (ante el débil, el de casta inferior), es violenta: tiene el impulso de exterminarlo, sin sentir ninguna responsabilidad, ya que carece de reflexión. Es cruel con los otros, pero no para que sea creativos, sino para gozar de su sufrimiento, pues esta bestia 'siente placer en destruir, en las voluptuosidades del triunfo y la crueldad'24.

¿Cómo entender estos dos aspectos del filosofar nietzscheano en general y de la Gran Política? ¿Son dos en realidad? Aceptar un dualismo en Nietzsche tendría la ventaja de que poder optar por una de sus vertientes y poder devaluar la otra como una etapa menos importante o quizá menos lúcida. Sería posible hacer a un lado las consideraciones sobre la ruptura con la humanidad, sobre la esclavitud y el exterminio, ya que sin duda, esto representa el mayor escollo del filosofar nietzscheano. La mayoría de los comentaristas (como Jaspers y Deleuze) ha tratado de soslayar este punto de vista, en especial porque él ha dado lugar a que Nietzsche sea considerado como antecesor del nacional socialismo. Otros intérpretes, como Lukács, han enfrentado esta perspectiva pero para satanizar al autor del Crepúsculo de los ídolos, y otros, como Foucault, la han reconocido como un testimonio más de la verdad que rige en la historia: la violencia y la lucha por el encarnizamiento ${ }^{25}$. Empero, tanto quienes soslayan la ruptura con la humanidad, como quienes hacen de ella la única perspectiva, atribuyen implícitamente un dualismo al filosofar nietzscheano, pues pareciera que el afán de comunicación y donación a la humanidad es algo totalmente inconexo y, por ende, inexplicable o digno de considerarse 'romántico', literario, no riguroso.

23 Cf. F. Nietzsche, La genealogía de la moral, p. 43.

24 Ibid., p. 48.

25 Cf. M. Foucault, «Nietzsche, la genealogía, la historia», en Microfísica del poder, tr. J. Varela y F. Álvarez-Uría, Madrid, La Piqueta, 1979. 
Según nuestra comprensión, no parece posible atribuir un dualismo implícito o explícito a un pensador que a todo lo largo de su obra trata de disolver cualquier escisión y dicotomía, que trata de evitar — como dice él- en La gaya ciencia toda «hemiplejia del pensamiento». De hecho, al concebir el filosofar como perspectivismo, juego y ensayo, Nietzsche no apuesta por una pluralidad inconexa o una parcialidad de las perspectivas. Lo que le interesaba era entender el todo: llegar a la unidad, pero no por una sola ruta, no por la univocidad o la identidad. Él nos invita a transitar por los abismos, por el caos e incluso por el descuartizamiento, para llegar a una unidad plural, más rica y plena de sentido. El perspectivismo es incomprensible sin la ligereza, la risa y la danza dionisíaca del pensamiento: danza desbordante y armónica, en la que todo fluye y todo se reincorpora. La danza es, en efecto, como sugiere Paul Valéry, la imagen suprema del pensar nietzscheano. Y Nietzsche mismo hace explícito en varias ocasiones su afán de unidad: «Mi cordura es haber sido muchas cosas y en muchos lugares, para poder llegar a ser una única $\cos a » 26$.

De tal suerte que no se justifica el desconocimiento de uno de los aspectos de la Gran Política. Por el contrario, parece necesario buscar el factor común a las dos perspectivas que ésta contiene. Ello no significa, empero, que veamos a Nietzsche como antecedente del nacional socialismo, ni que estemos haciendo una lectura malintencionada de su pensamiento dejándonos influir por su 'hermana incómoda', Elisabeth Förster.

Por el contrario, consideramos indispensable señalar, en primer lugar, que Nietzsche no rechazó sistemáticamente a los judíos de su tiempo; al revés, reconoció en ellos una mezcla de espiritualidad e interés por lo material, que los dotaba de superioridad. Él piensa que son los débiles y enfermos, los impotentes, los que envidian a los judíos. «Los antisemitas no perdonan a los hebreos que tengan esprit y dinero. Antisemita es uno de los nombres de los fracasados» 27 . Y en segundo lugar, Nietzsche estaba demasiado consciente de las debilidades y los vicios de Alemania como para propugnar por el dominio del pueblo alemán sobre el resto del mundo. Él quiso ser un apátrida.

26 F. Nietzsche, Ecce homo, p. 78.

27 F. Nietzsche, Voluntad de poderío, parágrafo 859. 
El modo como los nazis lo leyeron y buscaron apoyo en él, es cuestión que no puede atribuírsele directamente.

$Y$ sin embargo, este deslinde, no elimina el problema del exterminio del débil — quienquiera que éste sea. Visto en profundidad, tal exterminio hace imposible referirnos a un ethos nietzscheano, más aún, imposibilita la existencia de cualquier ética y cualquier aproximación a la humanidad, pues con él, se niega la igualdad interhumana. Y en esta medida, quedamos reducidos a identificarnos con un grupo particular y atender sólo a sus intereses, quedamos privados de categorías y comportamientos como la reciprocidad, la ayuda, la compasión, la justicia, la tolerancia. Sin igualdad interhumana triunfa el mal: la contraposición y la barbarie.

El problema consiste, entonces, en explicar a qué responde la desigualdad dentro de la unidad del pensamiento nietzscheano, a fin de determinar si ella predomina, en definitiva, sobre el intento de aproximación a la humanidad.

La unidad básica de este filosofar reside en un santo y profundo Sí a la vida que nos hace amarla tal y como es y advertir su inocencia radical, ya sea que nos muestre su faz de alegría o de dolor, de luz o de oscuridad, de abismo aterrador o de plenitud. Sólo que Nietzsche afirma la vida desde su propio ser desgarrado, desde una dualidad interna que marca el destino de su vida y su filosofía. Por un lado, hay en él la vivencia de lo excepcional de su individualidad. Él se sabe apartado de todos: «En una época absurdamente temprana — nos dice en Ecce homo-, a los siete años, ya sabía yo que nunca llegaría hasta mí una palabra humana»28. Y por otro lado, tanto en su vida como en su filosofía, según hemos visto, se esforzó por hallar la amistad y la comunicación. ¿Cómo si no explicar su amor por Wagner y su sufrimiento por la ruptura con él? ¿Cómo si no explicar el tono estimulante de su escritura y lo abundante de su obra?

Pero es precisamente su soledad y excepcionalidad lo que le hace pensar que los superiores están radicalmente separados del resto, más aún, le hace pensar que entre hombre y hombre hay una barrera infranqueable æy esto está presente, de cierta forma, incluso en Así babló Zaratustra. Sin demérito de lo desarrollado hasta aquí, hemos de reconocer que en realidad, este libro muestra el drama de la comuni- 
cación: ésta se busca en la misma medida en que queda imposibilitada. Sobresale en el Zaratustra, como hemos dicho, el afán de dar y aproximarse al hombre, pero en un momento dado, cuando el 'inmoralista' reflexiona sobre el lenguaje, manifiesta un profundo pesimismo sobre las relaciones humanas, le parece inevitable aceptar la incomunicación y la separación originaria. "iQué agradable es que existan palabras y sonidos! [...] ¿no son [éstos] acaso arcoiris y puentes ilusorios tendidos entre lo eternamente separado? A cada alma le pertenece un mundo distinto [...] toda otra alma es un trasmundo [eine Hinterwelt]. Entre las cosas semejantes es precisamente donde la ilusión miente del modo más hermoso; pues el abismo más pequeño es el más difícil de salvar» 29 .

De acuerdo con esto, el individuo está radicalmente solo, apartado, no incluye al otro dentro de sí. Por más esfuerzos que se realicen en pro de la interacción, entre hombre y hombre hay un abismo: cada uno gira en su propia órbita. Lo cual se confirma con la naturaleza de la voluntad de poder. Al ser sobreplena y sobreabundante, esta voluntad no conoce el vacío, el no-ser, la carencia; es pura luz sin oscuridad, sin contraste interno. Por ello, no puede dar cabida al 'tú'. Así nos explicamos que Zaratustra termine su recorrido en soledad, sin haber logrado la amistad: su sobreplenitud, su falta de vacío, le ha impedido aceptar al otro.

Y es esta soledad constitutiva la que abre el paso a la idea de la 'bestia rubia' y al aniquilamiento del débil. De acuerdo con ella, el individuo es autosuficiente, idéntico a sí mismo, desconoce la alteridad $y$, por ende, la radical igualdad y proximidad humanas. Cabe decir que en el fondo, Nietzsche se contrapone con esto al erōs platónico, a la interacción de plenitud y carencia (poros y penia) que nos permite estar simultáneamente unidos y separados, ser iguales y diferentes, y nos permite, en fin, reconocer que cada uno de nosotros posee un desdoblamiento interno entre 'yo' y 'tú', y que en consecuencia, «nada humano nos es ajeno»30.

Se lleva así al extremo — dicho sea de paso- la sentencia nietzscheana: «yo soy Platón al revés». Desde la primera expresión de

29 F. Nietzsche, "«El convaleciente», en Así habló Zaratustra.

30 Cf. E. Nicol, «La idea platónica del amor», en La idea del hombre, México, Stylo, 1946. 
la Gran Política, salta a la vista la relación con Platón, pues ambos hacen del filósofo un gobernante, pero a diferencia de Platón, Nietzsche considera que el artista no ha de ser excluido de la ciudad, sino que ha de gobernar, puesto que su naturaleza coincide con la del filósofo mismo. No obstante, el revés radical frente a Platón reside, a nuestro modo de ver, en concebir al hombre desde la soledad constitutiva.

Pero si esto es así, la perspectiva de la ruptura con la humanidad, del desprecio por el débil y de la 'bestia rubia' parece predominar sobre el pathos de universalidad y la pretensión de hacer un don a la humanidad. Y tal predominio concedería razón, de manera tácita, a quienes relacionan a Nietzsche con el nacional socialismo.

¿Imperan realmente la separación y el exterminio de los débiles? Atendiendo al conjunto del filosofar nietzscheano, parece forzoso admitir también que, pese a todo lo dicho, la soledad constitutiva no tiene la última palabra. Nietzsche fue plenamente consciente de los límites que ésta impone e intentó trascenderlos. Es cierto que él exalta la soledad y recomienda el «pathos de la distancia» y el huir de las «moscas del mercado». Pero en estos casos, habla de una soledad existencial, de un sano alejamiento de la banalidad de la vida pública y de una conveniente distancia con la complacencia del otro e incluso de nosotros mismos. Pero en cuanto advierte la falta de vínculo y de interacción humana que implica la sobreplenitud de la voluntad de poder, manifiesta en el Zaratustra, su deseo de romper tales límites y confiesa su 'ansia de ansiar': su deseo de lograr la auténtica proximidad con el otro. En «La canción de la noche» pronuncia palabras imborrables para todo aquel que quiera comprenderlo: «Luz soy yo: jay, si fuera noche! pero esta es mi soledad, el estar circundado de luz [...] No conozco la felicidad del que toma $[\ldots . . .]_{j}$ Oh desventura de todos los que regalan! ¡Oh eclipse de mi sol! ¡Oh ansia de ansiar! ¡Oh hambre ardiente en la saciedad! // Ellos toman de mí, pero ¿toco yo siquiera su alma?»31.

Se hace presente aquí un deseo de aceptar al otro, de recibirlo, de tomar algo de él. Zaratustra puede dar, pero debido a su sobreabundancia no puede recibir, éste es su límite, su pobreza; él no puede tocar en verdad el alma del otro, pues no tiene una necesidad originaria de complementarse con él. Sin embargo, el 'inmoralista' sufre por ello y reconoce, paradójicamente, el 'hambre de su saciedad'. 
Y no podría ser de modo distinto en un pensamiento que parte de la afirmación dionisíaca de la existencia, pues ¿no es acaso el otro parte esencial de la vida a la que se dice sí? Más aún, los débiles y malogrados también pueden recuperarse quizá por ésta afirmación. Ésta culmina en el 'eterno retorno de lo mismo' y en el amor fati: amor al destino, a la necesidad, amor a lo positivo y negativo del mundo: ‘sin detracción ni elección'. Aceptar irrestrictamente todo lo que ha ocurrido en la propia existencia y en el mundo en general, es el gran reto de Nietzsche, pues vio en ello la fórmula del amor a la vida y, por contradictorio que parezca, vio en ello también la vía suprema de la transformación. Él supo que a fuerza de repetir, tocamos fondo y nos abrimos a la renovación. «Transformar todo fue en así lo quise [y así lo querré para la eternidad]... sólo eso sería para mí redención», dice Zaratustra32.

Quizá pueda comprenderse así que Nietzsche proponga la figura de la 'bestia rubia', la aniquilación del débil y el nihilismo más extremo, porque acepta los aspectos destructivos de la vida en tanto ellos están presentes en el hombre moderno que vive la muerte de Dios. Pero no se convierte en nihilista para quedarse en la negación, sino para que, desde lo profundo del 'no', desde el extremo de la destrucción, pueda volver al 'sí. El exterminio del débil se puede entender, entonces, como un tránsito, como una intensificación de la ida de la 'aristocracia de sangre' para que en el máximo de la exclusividad, se pueda aceptar a los débiles como parte de lo que eternamente ha sido y será, como interlocutor necesario de los superiores.

Lo cual coincide con el hecho de que Nietzsche mismo fue un enfermo que tuvo que luchar contra su debilidad y se vio forzado a aceptar la enfermedad como parte de su propia conquista de la salud: «[...] para un ser típicamente sano [...] el estar enfermo puede constituir incluso un enérgico estimulante para vivir, para más vivir [...] Un ser bien constituido [...] saca ventaja de las contrariedades; lo que no le mata le hace más fuerte»33.

Aceptar a los débiles y malogrados debió ser para él, una exigencia proveniente de su propia salud, de su afán por trascender el nihilismo moderno gracias al amor fati y el eterno retorno.

32 F. Nietzsche, «De la redención», en Así habló Zaratustra.

33 F. Nietzsche, Ecce homo, p. 24. 
De cualquier modo, hemos de reconocer que se trata de un tránsito peligroso. Nietzsche lo sabe: «mi peligro es la náusea hacia el hombre» — dice en Ecce homo. Pero él quiso asumir éste riesgo, pues confiaba en el poder afirmativo de su pensamiento. En uno de sus fragmentos póstumos más sorprendentes leemos: «Recorrer todos los círculos del alma moderna, haber conocido todos sus rincones: ésta es mi ambición, mi tortura y mi felicidad. Superar realmente el pesimismo: el resultado será una mirada goethiana, llena de amor y de buena voluntad»34.

En este sentido, puede decirse que el auténtico peligro de Nietzsche, lo que ha permitido a algunos movimientos políticos destructivos servirse de él, reside en ser leído de manera parcial, en no ser asumido desde el 'sí', desde el amor fati, el cual es, sin duda, el eje axial de su universo filosófico.

Hemos de reconocer que este amor es problemático y que no alcanza la riqueza y profundidad del erōs platónico, pues ciertamente, no da cabida al desdoblamiento, a la necesidad originaria del otro; pero también hemos de aceptar que es amor: entrega, trascendencia del 'yo' autorreferente, y como tal, él valida el afán nietzscheano de hacer un don a la humanidad. La esperanza predomina sobre toda ruptura. Una y otra vez aparece el impulso a trascender la soledad, el aislamiento y la destrucción. Y por esto, cabe encontrar en Nietzsche, pese a todo, una posible ética afirmadora de la vida, una ética alegre y feliz 35 .

Como última referencia para estas convicciones recordemos las siguientes palabras de La gaya ciencia: «El que sabe considerar la historia del hombre en su conjunto como su historia, siente, en una enorme generalización, toda la aflicción del enfermo que sueña con la salud, del viejo que sueña con su juventud [...] del héroe [...] [que] conserva las heridas y el pesar por la muerte de un amigo. Pero llevar esta suma enorme de miseria de toda especie [...] y ser, al mismo tiempo, el héroe que saluda [...] la venida de la aurora [...] debería tener por resultado [...] la dicha de un dios pleno de poderío y de amor $[\ldots .$.$] una dicha que semejante al sol de la tarde [\ldots .$.$] no se sentirá$ plenamente rico sino cuando el más pobre pescador reme con remos de oro. Esta dicha divina se llamará entonces humanidad»36.

34 F. Nietzsche, La voluntad de poderío, § 1024.

35 Cf. L. Sagols, ¿Ética en Nietzsche?, México, unam, 1997.

36 F. Nietzsche, «El eterno retorno (La gaia scienza)», en Obras completas, vol. III. 